\title{
Subnormal sensitivity of neutrophils to complement split product C5a in rheumatoid arthritis: relation to complement catabolism and disease extent
}

\author{
JENS ELMGREEN AND TROELS MØRK HANSEN
}

From the Medical Gastroenterological Department, Herlev Hospital, and Department of Rheumatology Hvidovre Hospital, University of Copenhagen, Copenhagen, Denmark

SUMMARY The capacity of circulating neutrophils for activation by complement was studied ini outpatients with classical or definite rheumatoid arthritis during treatment with dextropropoxy- $\vec{\sim}$ phene only. Analysis of dose-response in the Boyden chamber assay of chemotaxis showed that sensitivity to the potent, complement derived anaphylatoxin, C5a, was markedly decreased ${ }_{\supset}^{-}$ especially in those patients with few joints involved. In contrast, peak response to C5a was withinf the normal range. Increased complement $3 \mathrm{c}$ split products in plasma of the patients suggestect involvement of complement cascade reactions. Subnormal sensitivity of neutrophils to phlogistic mediators released by complement may tend to limit their recruitment and potentially tissueos destroying secretion locally in rheumatoid arthritis.

Key words: chemotaxis, complement 3, complement 5, inflammation.

Neutrophils are abundant locally in rheumatoid arthritis, both in the synovial fluid ${ }^{1}$ and at the interphase of cartilage with pannus. ${ }^{2}{ }^{3}$ Lysosomal enzymes and other mediators of inflammation released by neutrophils after activation with immune complexes or complement split products may account, at least in part, for rheumatoid inflammation and tissue destruction. ${ }^{4}$

Cellular factors may be involved in limiting neutrophil recruitment from peripheral blood. Recently demonstrated, specific receptors ${ }^{5}$ for the major, complement derived chemotactic factor, $\mathrm{C}^{2} \mathrm{a}^{6}$ may be selectively desensitised at least during in-vitro conditions. ${ }^{78}$ In experimental animals complement appears to be essential for accumulation of neutrophils in diverse acute inflammatory reactions. ${ }^{9-11}$ Raised circulating levels of C3 split products in rheumatoid arthritis and a positive concentration gradient of the split product between synovial fluid and plasma ${ }^{12}$ suggest involvement of complement with release of phagocyte activating split products.

Accepted for publication 21 January 1985.

Correspondence to Dr Jens Elmgreen, Medical Gastroenterological Department C, Herlev Hospital, DK-2730 Herlev, Denmark.

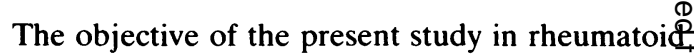
arthritis was to assess the capacity of circulating neutrophils for activation of chemotaxis by the major, complement derived chemotactic factor C5a. Plasma c split product of C3 (C3c) was quantified as a parameter of complement catab olism. C3c is released by activation of both the classical and alternative pathways of complement.

\section{Materials and methods}

PATIENT POPULATION

Fifteen consecutive outpatients with classical op definite rheumatoid arthritis according to the criteria of the American Rheumatism Associations were studied. Exclusion criteria were: (1) treatmenty with gold compounds, penicillamine, or steroids within six preceding weeks; and (2) complicating infections or conditions, such as atopy, affecting the immune system. Aspirin and non-steroidal antiE inflammatory drugs were withdrawn for a median o $\$$ 10 days, range 7-18 days, and during this washout period pain was controlled with dextropropoxyo phene only. All patients were interviewed an $\Phi$ examined by the same physician before drawing blood samples for investigation on the same day? The patients, 13 females and two males, had 
median age of 63 years, range 19-73 years. Clinical data and routine laboratory values of the patients are given in Table 1.

Fifteen healthy volunteers including hospital or laboratory personnel on no medication acted as controls. They were 11 females, and four males, aged 23-67 years, median 46 years. All patients and controls. They were 11 females and four males, the protocol had been accepted by the region's scientific-ethical committee for studies in humans.

\section{R E A G E N T S}

Casein (alkalilöslich, Merck, Darmstadt, FRG), $\varepsilon$ aminocaproic acid (Meco Benzon, Copenhagen, Denmark), ethylene diaminetetra-acetate (EDTA) (Merck), $3 \mu \mathrm{m}$ pore size Sartorius filters with a thickness of $200 \mu \mathrm{m}$ (Sartorius, Göttingen, FRG), purified human albumin (Behringwerke, Marburg, FRG), Lymfoprep (Nygaard, Oslo, Norway), methylcellulose (Apodan, Copenhagen, Denmark), Sephadex G75 gel (Pharmacia Fine Chemicals, Uppsala, Sweden), standard human serum (Behringwerke), and zymosan A (Sigma, St Louis, USA) were employed. Rabbit antibodies to human $\mathrm{C} 3 \mathrm{c}, \mathrm{C} 3 \mathrm{~d}$, and $\mathrm{C} 5$ and rabbit immunoglobulins from non-immunised rabbits were from DAKO immunoglobulins, Copenhagen, Denmark. Gey's solution was prepared according to the method of Wilkinson. ${ }^{14}$

\section{H E MOATTRA CTANTS}

Complement anaphylatoxin C5a was prepared from complement activated plasma according to proved principles ${ }^{15} 16$ by: (1) preincubation of heparin plasma $(2 \mathrm{IU} / \mathrm{ml})$ overnight with $1 \mathrm{M} \varepsilon$-aminocaproic acid at $4^{\circ} \mathrm{C}$; (2) activation with zymosan $(20 \mathrm{~g} / \mathrm{l})$ for 75 minutes at $37^{\circ} \mathrm{C}$; and (3) chromatography on Sephadex G75. ${ }^{17}$ Chemotactic fractions eluted in the molecular weight region of 15000 were pooled, freeze dried, dialysed against Gey's solution, frozen in liquid nitrogen, and kept at $-80^{\circ} \mathrm{C}$ until assessment.

Identically prepared, low molecular weight fractions of non-activated plasma did not show chemotactic activity. Moreover, activity could be abolished by incubation with antibody to $\mathrm{C} 5$ but not with antibody to $\mathrm{C} 3$ or antibody from non-immunised rabbits. ${ }^{17}$ Complete separation of this chemotactic preparation from native complement components $\mathrm{C} 3$ and C5 of the plasma was shown by fused rocket immunoelectrophoresis ${ }^{18}$ of individual fractions against specific antibody. Casein $(5 \mathrm{~g} / \mathrm{l})$ was dissolved in modified Gey's solution at $\mathrm{pH} 12$ according to the method of Wilkinson. ${ }^{14}$

\section{NEUTROPHIL CHEMOTAXIS}

Neutrophils were purified from peripheral blood drawn in EDTA $(10 \mathrm{mM})$. After a methylcellulose sedimentation of the red cells, buffy coat leucocytes were further fractionated by gradient centrifugation on Lymfoprep, washed twice, and adjusted to $2 \times 10^{9}$ cells/l in Gey's solution with albumin $(2 \%)$.

Activation of neutrophil chemotaxis was assessed in Sartorius $3 \mu \mathrm{m}$ pore size filters placed in modified Boyden chambers. ${ }^{14}$ Experiments were run for 45 minutes at $37^{\circ} \mathrm{C}$ and the filters were fixed, stained, and read by the leading front technique. ${ }^{19}$

A panel of C5a dilutions in Gey's solution, and casein or Gey's solution alone were placed in the lower compartment of the Boyden chambers. Sensitivity to C5a was expressed in titres of the activator, corresponding to a half peak response. Values of non-activated, spontaneous migration towards Gey's solution were subtracted before calculation of the titres by linear intrapolation in the ascending part of the dose-response curves. All results are based on medians of nine determinations on two filters.

\section{CIRCULATING C3C}

Split products of $\mathrm{C} 3$ were quantified in EDTA plasma $(10 \mathrm{mM})$, frozen in liquid nitrogen, and kept at $-80^{\circ} \mathrm{C}$ for less than three months before quantification by intermediate gel technique. ${ }^{20}$ Precipitation of native $\mathrm{C} 3$ and $\mathrm{C} 3$ split products with $\mathrm{d}$ specificity was accomplished in the intermediate gel by antibody specific for $\mathrm{C} 3 \mathrm{~d}$, permitting $\mathrm{C} 3 \mathrm{c}$ rockets to be formed in the upper gel by $\mathrm{C} 3 \mathrm{c}$ antibody. The specificity of this method has previously been demonstrated. $^{20}$ Standard human serum from Behringwerke containing $\mathrm{C} 3$ in the form of $\mathrm{C} 3 \mathrm{c}$ only $(0.92 \mathrm{~g} / \mathrm{l})$ served as antigen standard.

Table 1 Clinical data and routine laboratory values of 15 patients with rheumatoid arthritis

\begin{tabular}{llllll}
\hline $\begin{array}{l}\text { Affected joints } \\
(\text { number })\end{array}$ & $\begin{array}{l}\text { Morning stiffness } \\
(\text { min })\end{array}$ & $\begin{array}{l}\text { Disease duration } \\
(\text { years })\end{array}$ & $\begin{array}{l}\text { Sedimentation rate } \\
(\mathrm{mm} / \mathrm{h})\end{array}$ & $\begin{array}{l}\text { C-reactive protein* } \\
(\mathrm{mg} / \mathrm{l})\end{array}$ & $\begin{array}{l}\text { Rose-Waaler } \\
\text { titre }\end{array}$ \\
\hline 12 & 45 & 14 & 31 & 32 & 160 \\
$(0-54)$ & $(0-300)$ & $(3-36)$ & $(2-110)$ & $(3-106)$ & $(40->5120)$ \\
\hline
\end{tabular}

Values are median with range in parentheses.

${ }^{*}$ Reference interval: $\leqslant 10 \mathrm{mg} / \mathrm{l}$. 


\section{S T A T IS T I CS}

The Mann-Whitney rank sum test and the Spearman rank correlation test were applied.

\section{Results}

Individual dose-response curves for $\mathrm{C5a}$ activation of neutrophil chemotaxis all increased to reach a peak value within the panel of titres tested. Further increases of activator concentration led to declining responses. Representative dose-response curves for rheumatoid arthritis patients and normal controls are given in Fig. 1. Table 2 shows neutrophil responses to $\mathrm{C} 5 \mathrm{a}$ in total patient and control groups.

Sensitivity of peripheral neutrophils to C5a was expressed in titres corresponding to a half maximal response in individual tests. Medians were 40 in rheumatoid arthritis patients and 82 in healthy

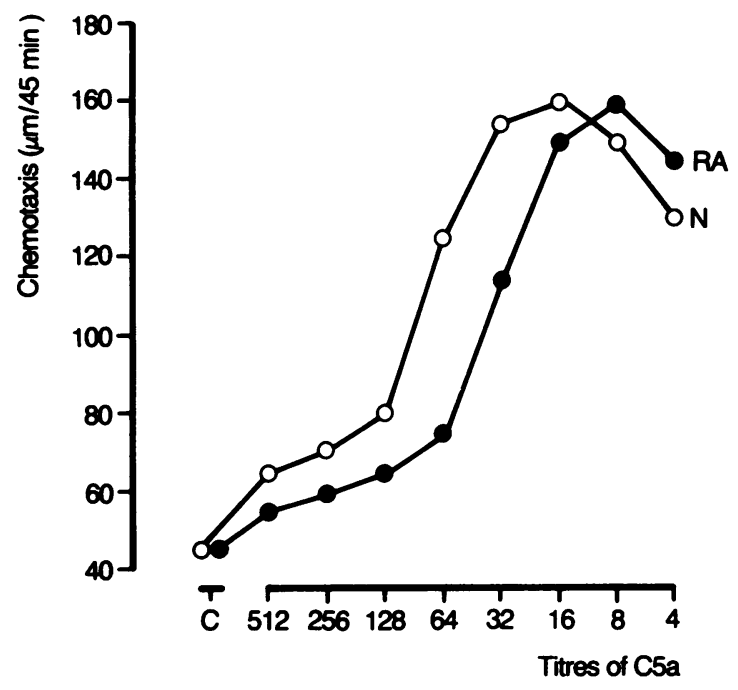

Fig. 1 Representative dose-response curves for neutrophil chemotaxis to C5a in one patient with rheumatoid arthritis $(R A)$ and in one normal control (N). Migration was activated by twofold dilutions of C5a or was assessed in the absence of attractant, control (C). volunteers. This twofold decrease of sensitivity to $\frac{0}{n}$. specific stimulation was significant at the $p<0.005 \Rightarrow$ level, with subnormal values in 10 to 15 rheumatoid arthritis tests (Fig. 2). In contrast, peak response of neutrophils to $\mathrm{C} 5 \mathrm{a}$ was normal in the patients $(\mathrm{p}>0 \cdot 10$, Table 3$)$.

Non-specific activation with casein and the spon- taneous motility of the cells tested with Gey'sin

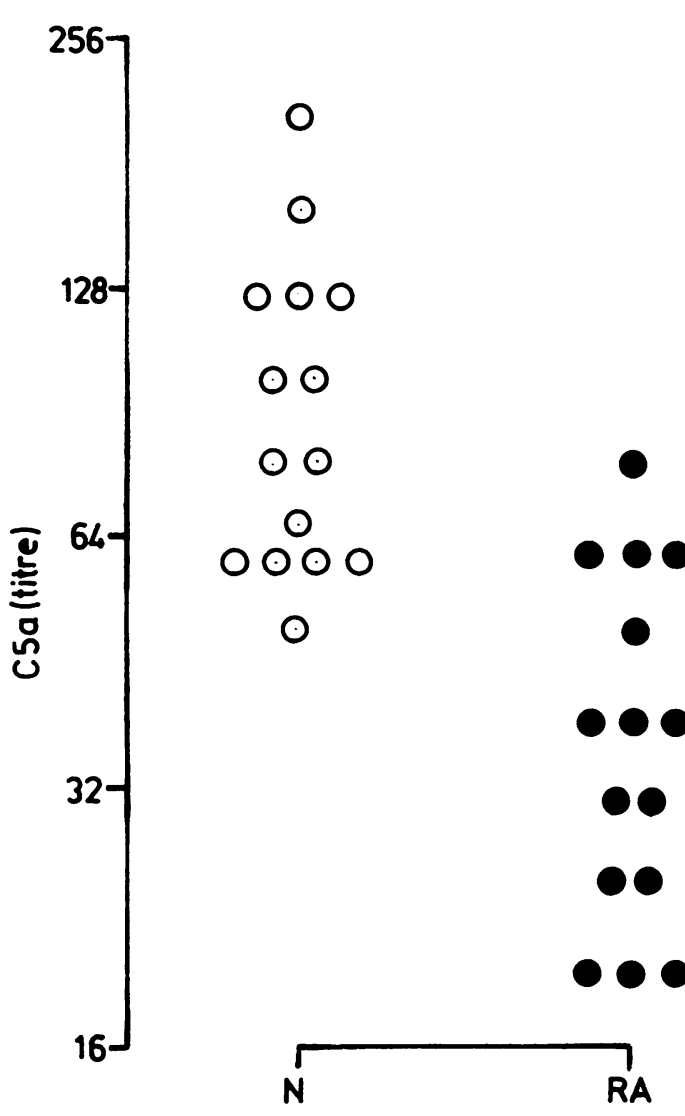

Fig. 2 Decreased sensitivity to C5a in patients with rheumatoid arthritis $(R A)$ compared with normal controls $(N)(p<0.005)$. Individual titres of C5a corresponding to half maximal response are given.

Table 2 Neutrophil chemotaxis to twofold dilutions of C5a

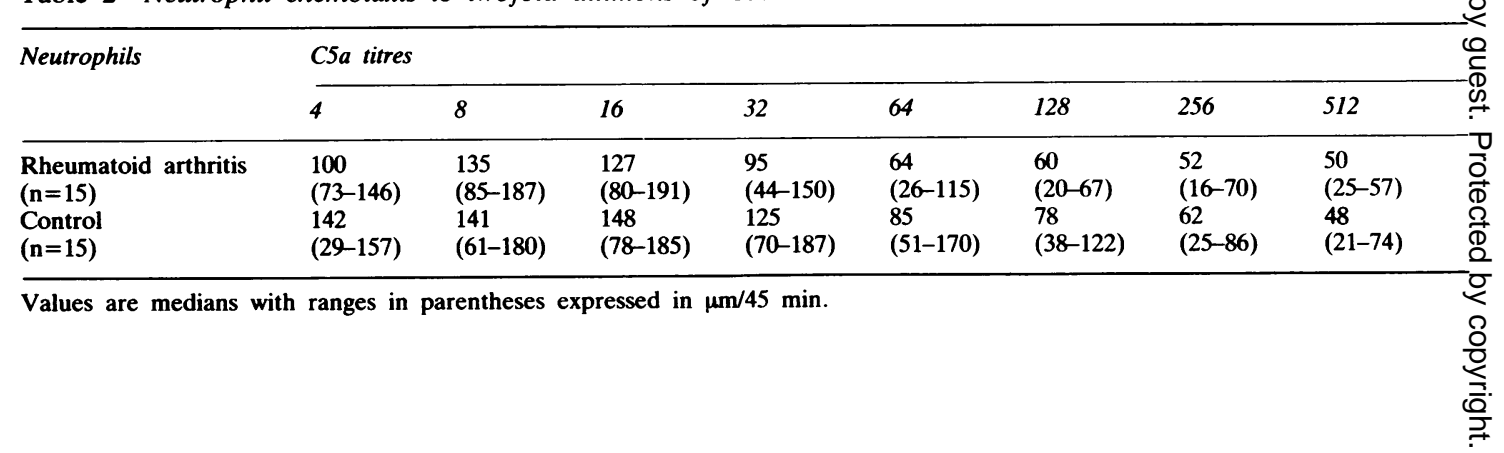


Table 3 Neutrophil chemotaxis in rheumatoid arthritis (RA)

\begin{tabular}{llll}
\hline Neutrophils & \multicolumn{2}{l}{ Chemotaxis* } \\
\cline { 2 - 4 } & Casein & C5a & Gey's solution \\
\hline Rheumatoid arthritis & 96 & 142 & 45 \\
$(\mathrm{n}=15)$ & $(82-122)$ & $(85-191)$ & $(12-52)$ \\
$\begin{array}{l}\text { Control } \\
(\mathrm{n}=15)\end{array}$ & 106 & 157 & 46 \\
& $(75-131)$ & $(120-187)$ & $(23-54)$ \\
\hline
\end{tabular}

${ }^{*}$ Values are median with range in parentheses expressed in $\mu \mathrm{m} / 45$ min.

Casein concentration $5 \mathrm{~g} / \mathrm{l}$ : $\mathrm{C} 5 \mathrm{a}$ titre yielding maximal response in individual tests.

solution in both chamber compartments did not differ between groups of rheumatoid arthritis patients and normal controls $(p>0 \cdot 10)$ (Table 3$)$.

Values of sensitivity to C5a correlated negatively with numbers of affected joints $\left(r_{s}=-0 \cdot 66, p<0 \cdot 01\right.$, $\mathrm{n}=15$ ) (Fig. 3). Patients with a large number of swollen and/or painful joints all reacted normally in the sensitivity test (Fig. 3). No significant correlation could be established between other clinical parameters such as duration of the disease or duration of morning stiffness and any neutrophil function test $(p>0 \cdot 10)$.

Levels of the $c$ split product of $\mathrm{C} 3(\mathrm{C} 3 \mathrm{c})$ in the circulation were slightly but significantly raised in rheumatoid arthritis patients $(p<0.025)$ (Fig. 4). This indicator of $\mathrm{C} 3$ catabolism did not correlate with clinical parameters recorded.

Cell suspensions ready for chemotaxis experi-

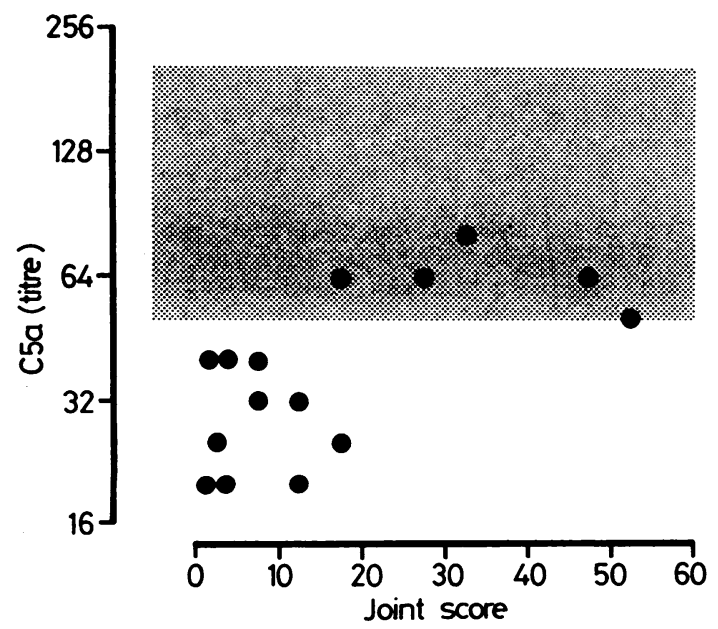

Fig. 3 Negative correlation of C5a sensitivity with numbers of affected joints in rheumatoid arthritis patients $\left(r_{s}=-0.66\right.$, $p<0.01, n=15)$. C5a titres correspond with a half maximal response. Hatched area indicates reference interval.

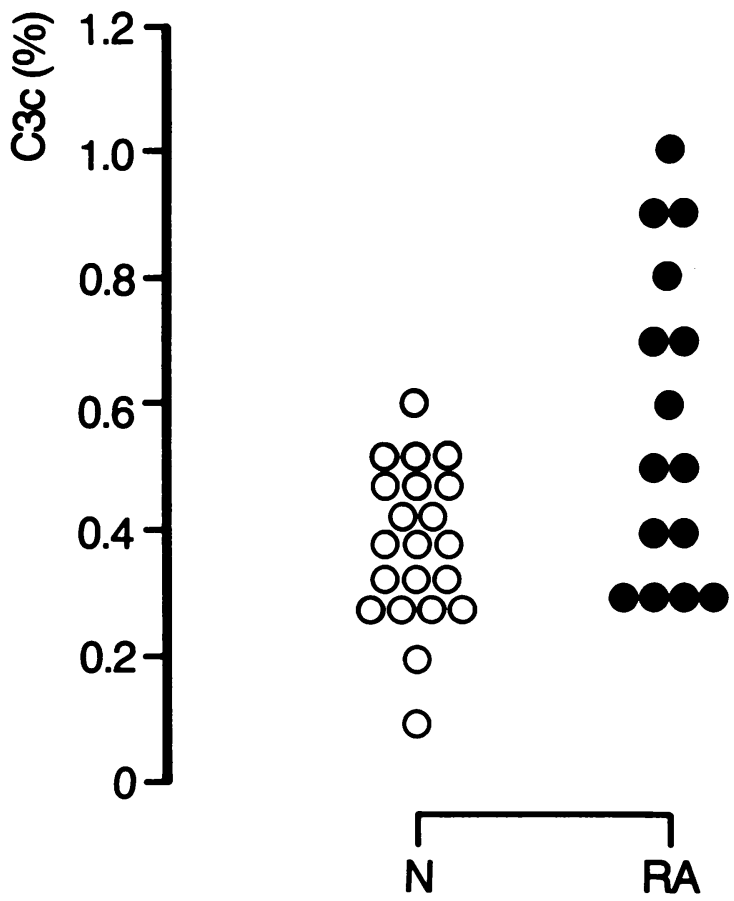

Fig. 4 Raised levels of $c$ split products of $\mathrm{C} 3(\mathrm{C} 3 \mathrm{c})$ in the circulation of rheumatoid arthritis patients $(R A)$ compared with normal controls $(N)(p<0.025)$.

ments contained $\geqslant 96 \%$ neutrophils both in patients and controls, and recovery of these responding cells was $45 \%$.

\section{Discussion}

The present study shows a significant abnormality of circulating neutrophils in well established rheumatoid arthritis. Cellular sensitivity to complement 5a was decreased by a factor of two as found from studies of chemotaxis in the proved Boyden chamber assay. ${ }^{14}$ Normal peak response by $\mathrm{C} 5$ a suggested an unaffected basic cell function. The findings are compatible with a competitive inhibition of complement 5a receptors on neutrophils. Normal chemotaxis to casein seems to exclude the possibility of major, intrinsic defects of cellular locomotion. ${ }^{21}$

A selective refractoriness of circulating neutrophils to $\mathrm{C} 5 \mathrm{a}$ has previously been reported during haemodialysis leading to intravascular activation of complement. ${ }^{22}$ Moreover, incubation of neutrophils with purified $\mathrm{C5a}$ in vitro induced a selective desensitisation of specific receptors, ${ }^{78}$ whereas casein responses remained unaffected. ${ }^{7}$ In rheumatoid arthritis, similarly, intravascular activation of complement may be primary to the cellular dysfunction 
phenomenon. Hypercatabolism of complement C3, that is, activation of complement by either the classical or alternative pathway, was suggested in the present study by the demonstration of an increase in the level of $\mathrm{C} 3 \mathrm{c}$ split product in the circulation. This finding confirmed previous observations of increased C3d, another C 3 split product, assessed by an entirely different technique. ${ }^{12}$

Based on the studies of normal leucocytes incubated in vitro with $\mathrm{C} 5 \mathrm{a}$ the possibility of a role for specific desensitisation of C5a receptors in limiting potentially harmful neutrophil functions in inflammation has been discussed. ${ }^{78}$ The present study of patients with rheumatoid arthritis suggests a modulating influence of C5a dysfunction for the extent of rheumatic inflammation. Values of dysfunction correlated negatively with numbers of affected joints, the cell function being normal in all patients with many joints involved. Neutrophil dysfunction in rheumatoid arthritis may act in concert with humoral inhibitors ${ }^{23-25}$ to produce the decreased migration during simulated in-vivo conditions in skin window chambers. ${ }^{26}$

In Crohn's disease a similar association of defective neutrophil accumulation in skin window chambers, ${ }^{27}$ hypercatabolism of complement $\mathrm{C} 3{ }^{28}{ }^{29}$ and decreased sensitivity to $\mathrm{C} 5 \mathrm{a}^{30}$ suggest that a selective 'down regulation' of neutrophil function may be operative in diverse chronic inflammatory conditions. Intravascular activation of complement may be the common denominator.

H Kargaard is thanked for excellent technical assistance and Jane Holm Nielsen for typing the manuscript.

\section{References}

1 Palmer D G. Total leucocyte enumeration in pathologic synovial fluid. Am J Clin Pathol 1968; 49: 812.

2 Mohr W, Wild A, Wolf H P. Role of polymorphs in inflammatory cartilage destruction in adjuvant arthritis of rats. Ann Rheum Dis 1981; 40: 171-6.

3 Mohr W, Westerhellweg H, Wessinghage D. Polymorphonuclear granulocytes in rheumatic tissue destruction. III. An electron microscopic study of PMNs at the pannus-cartilage junction in rheumatoid arthritis. Ann Rheum Dis 1981; 40: 396-9.

4 Weissman G. Activation of neutrophils and the lesions of rheumatoid arthritis. J Lab Clin Med 1982; 100: 322-33.

5 Chenoweth D E, Hugli T E. Demonstration of a specific C5a receptor on intact human polymorphonuclear leucocytes. Proc Natl Acad Sci USA 1978; 75: 3943-7.

6 Fernandez H N, Henson P M, Otani A, Hugli T E. Chemotactic response to human $\mathrm{C} 3 \mathrm{a}$ and $\mathrm{C} 5 \mathrm{a}$ anaphylatoxins. I. Evaluation of $\mathrm{C3a}$ and $\mathrm{C5a}$ leukotaxis in vitro and under simulated in vivo conditions. J Immunol 1978; 120: 109-15.

7 Henson P M, Zanolari B, Schwartzman N A, Hong S R. Intracellular control of human neutrophil secretion. $J$ Immunol 1978; 121: 851-5.

8 O'Flaherty J T, Kreutzer D L, Showell H J, Vitkauskas G, Becker E L, Ward P A. Selective neutrophil desensitization to chemotactic factors. J Cell Biol 1979; 80: 564-72.

9 Cochrane C G, Müller-Eberhardt H J, Aikin B S. Depletion of plasma complement in vivo by a protein of cobra venom: its. effect on various immunologic reactions. J Immunol 1970; 105: $\overrightarrow{7}$ 55-69.

10 DeShazo C V, McGrade M T, Henson P M, Cochrane C G.O The effect of complement depletion on neutrophil migration in $\bar{C}$ acute immunologic arthritis. J Immunol 1972; 108: 1414-9. क

11 Wiener S, Lendvai S, Rogers B, Urivetzky M, Meilman E. Nonimmume chemotaxis in vivo. Am J Pathol 1973; 73: 807-16. ¿

12 Nydegger U E, Zubler R H, Gabuy R, et al. Circulating complement breakdown products in patients with rheumatoid ${ }^{S}$ arthritis. J Clin Invest 1977; 59: 862-8.

13 Atkinson J P, Frank M M. Complement. In: Parker C W, ed. Clinical immunology. Philadelphia: Saunders, 1980.

14 Wilkinson P C. Chemotaxis and inflammation. Edinburgh: Churchill Livingstone, 1974.

15 Vallota E H, Müller Eberhardt H J. Formation of C3a and C5a anaphylatoxins in whole human serum after inhibition of the anaphylatoxin inactivator. $J$ Exp Med 1973; 137: 1109-13. :

16 Goldstein I M, Roos D, Kaplan H B, Weismann G. Complement $\infty$ and immunoglobulins stimulate superoxide production by hu- $\rightarrow$ man leucocytes independently of phagocytosis. J Clin Invest ${ }^{+}$ 1975; 56: 1155-63.

17 Elmgreen J, Berkowicz A, Sørensen H. Defective release of C5a related chemo-attractant activity from complement in Crohn's disease. Gut 1983; 24: 525-31.

18 Svendsen P J. Fused rocket immunoelectrophoresis. In: Axelsen N H, Kröll J, Weeke B, eds. A manual of quantitative? immunoelectrophoresis. Oxford: Blackwell, 1977.

19 Zigmond S H, Hirsch J G. Leucocyte locomotion and chemo-ळ taxis. $J$ Exp Med 1973; 137: 387-411.

20 Berkowicz A, Rosenkvist J, Sørensen H. A single stepD immunoelectrophoresis method for the quantitation of comp-O lement C3c in biological fluids. J Immunol Methods 1983; 60: 277-88.

21 Pedersen Bjerregaard J, Vindeløv L, Philip P, et al. Varyingڤ̆

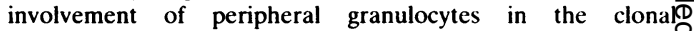
abnormality -7 in bone marrow cells in preleucaemia secondary to treatment of other malignant tumors. Cytogenetic resultso compared with. results of flow cytometric DNA-analysis and neutrophil chemotaxis. Blood 1982; 60: 172-9.

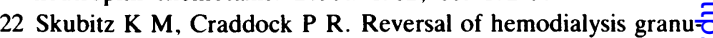
locytopenia and pulmonary leucostasis - a clinical manifestation of selective down-regulation of granulocyte response to $\mathrm{C5}_{\mathrm{acs}}$ arg. $J$ Clin Invest 1981; 67: 1383-91.

23 Kemp A S, Roberts-Thomson P, Neoh S H, Brown S. Inhibition of neutrophil migration by sera from patients with: rheumatoid arthritis. Clin Exp Immunol 1979; 36: 423-9.

24 Hanlon S M, Panayi G S, Laurent R. Defective polymorphonu clear leucocyte chemotaxis in rheumatoid arthritis associatedo with a serum inhibitor. Ann Rheum Dis 1980; 39: 68-74.

25 Walker J R, Smith M J H. An inhibitor of leucocyte movement in the plasma of patients with rheumatoid arthritis. Ann Rheum Dis 1980; 39: 563-5.

26 Walker J R, James D W, Smith M J H. Directed migration of circulating polymorphonuclear leucocytes in patients with $\mathrm{N}$ rheumatoid arthritis: a defect in the plasma. Ann Rheum Dis 1979; 38: 215-8.

27 Segal A W, Loevi G. Neutrophil dysfunction in Crohn's disease. Lancet 1976; ii: 219-21.

28 Hodgson H J F, Potter B J, Jewell D P. C3 metabolism in ulcerative colitis and Crohn's disease. Clin Exp Immunol 1977. क 28: $490-5$.

29 Elmgreen J, Berkowicz A, Sørensen H. Hypercatabolism of complement in Crohn's disease - assessment of circulating C.3c. $\bar{O}$ Acta Med Scand 1983; 214: 403-7.

30 Elmgreen J. Subnormal activation of phagocytes by comple- $\Omega$ ment in chronic inflammatory bowel disease? Neutrophi chemotaxis to complement split product C5a. Gut 1984; $25: 0$ 737-42. 